Section Editor

John J. Millichap, MD

Pearls \& Oy-sters:

\title{
CNS lymphoma in a patient with relapsing-remitting multiple sclerosis treated with interferon
}

Sharon Chiang, $\mathrm{PhD}$

Navin K. Kesari, MD

Anthony Bradshaw, MD

Wendy Chen, MD

Rohini Samudralwar, MD

Ammar M. Alobaidy, MD

Joseph S. Kass, MD, JD

Correspondence to

Dr. Kass:

kass@bcm.edu
Supplemental data at Neurology.org

\section{PEARLS}

- Early clinical suspicion for CNS lymphoma is important for appropriate diagnosis and treatment in patients with preexisting multiple sclerosis (MS).

- Although research suggests a potential pathophysiologic association between interferon $\beta$ and primary CNS lymphoma, current clinical evidence does not suggest a definitive link.

- Several overlapping radiologic features are shared between CNS lymphoma and tumefactive MS, including the presence of peripheral contrast enhancement, mass effect, and edema.

\section{OY-STERS}

- Both acute MS attacks and CNS lymphoma are sensitive to corticosteroids. However, prolonged dependence on corticosteroids for symptom control should prompt suspicion of CNS lymphoma.

- Although there is significant radiologic overlap between CNS lymphoma and tumefactive MS, radiologic discriminatory features between CNS lymphoma and tumefactive MS include degree of mass effect, enhancement patterns, and apparent diffusion coefficient diffusion restriction.

CASE REPORT A 61-year-old right-handed woman with relapsing-remitting MS (RRMS) on interferon $\beta$-1a since 2007 presented in January 2017 with a 4-day history of binocular diplopia, right eye ptosis, and left-sided weakness. She was diagnosed at age 26 after presenting with bilateral peripheral visual field cuts and treated with IV methylprednisolone and interferon $\beta-1 \mathrm{~b}$. She experienced flares approximately every 2 years until she was started on interferon $\beta$-1a in 2007 and had no relapses until her current presentation to our institution.

Neurologic examination on presentation was significant for incomplete right third cranial nerve palsy with ptosis and limited right eye adduction as well as left pyramidal weakness. MRI brain with and without contrast showed stable supratentorial white matter lesions consistent with MS, as well as a new T2-weighted 1.6-cm hyperintense right thalamocapsular lesion extending to the midbrain and pons with local mass effect and partial effacement of the third ventricle (figure, $\mathrm{A}-\mathrm{C}$ ). Initially, the patient's presentation was ascribed to a new tumefactive demyelinating lesion given its larger size and mass effect. She was treated with 5 days of IV methylprednisolone $1,000 \mathrm{mg}$ daily with return to her prior neurologic baseline. She was discharged home with a 2 -week oral prednisone taper.

Two weeks after discharge, the patient returned with recurrence of diplopia and right eye ptosis. Neurologic examination revealed incomplete rightsided ptosis, moderate limitation of right eye adduction, and new sluggishly reactive right pupil. Motor strength was $4 / 5$ on the left primarily affecting the deltoid and finger abductors and normal tone throughout. Repeat MRI brain with and without contrast demonstrated interval doubling in size of the right thalamo-mesencephalic lesion (from 1.6 to $3.2 \mathrm{~cm}$ ) with edema now diffusely involving the right thalamus, right midbrain, and right pons (figure, D-F). CSF studies showed 7 white blood cells (normal 0-5) with $84 \%$ lymphocytes, glucose $52 \mathrm{mg} / \mathrm{dL}$ (normal 50-80 $\mathrm{mg} / \mathrm{dL}$ ), protein $78.6 \mathrm{mg} / \mathrm{dL}$ (normal $15-45 \mathrm{mg} / \mathrm{dL}$ ), and negative Gram stain. Epstein-Barr virus was not detected, and flow cytometry was negative for atypical cells. Cytology was negative for malignancy. The patient was treated with 2 sessions of plasmapheresis but by hospital day 6 , the patient's right oculomotor palsy progressed to completion with nonreactive and dilated pupil, complete ptosis, and associated oculomotor paralysis as well as interim progression of left hemiparesis to new left lower facial paralysis and 2/5 motor strength primarily affecting the deltoid, upper extremity extensor, and hip flexor. The significant mass effect out of proportion to that expected with tumefactive demyelination in a patient of this age, as well as the pattern of apparent diffusion coefficient diffusion restriction (figure, $\mathrm{H}$ and I), were suspicious for $\mathrm{CNS}$

From the School of Medicine (S.C.) and Department of Neurology (N.K.K., A.B., W.C., R.S., A.M.A., J.S.K.), Baylor College of Medicine, Houston, TX.

Go to Neurology.org for full disclosures. Funding information and disclosures deemed relevant by the authors, if any, are provided at the end of the article. 

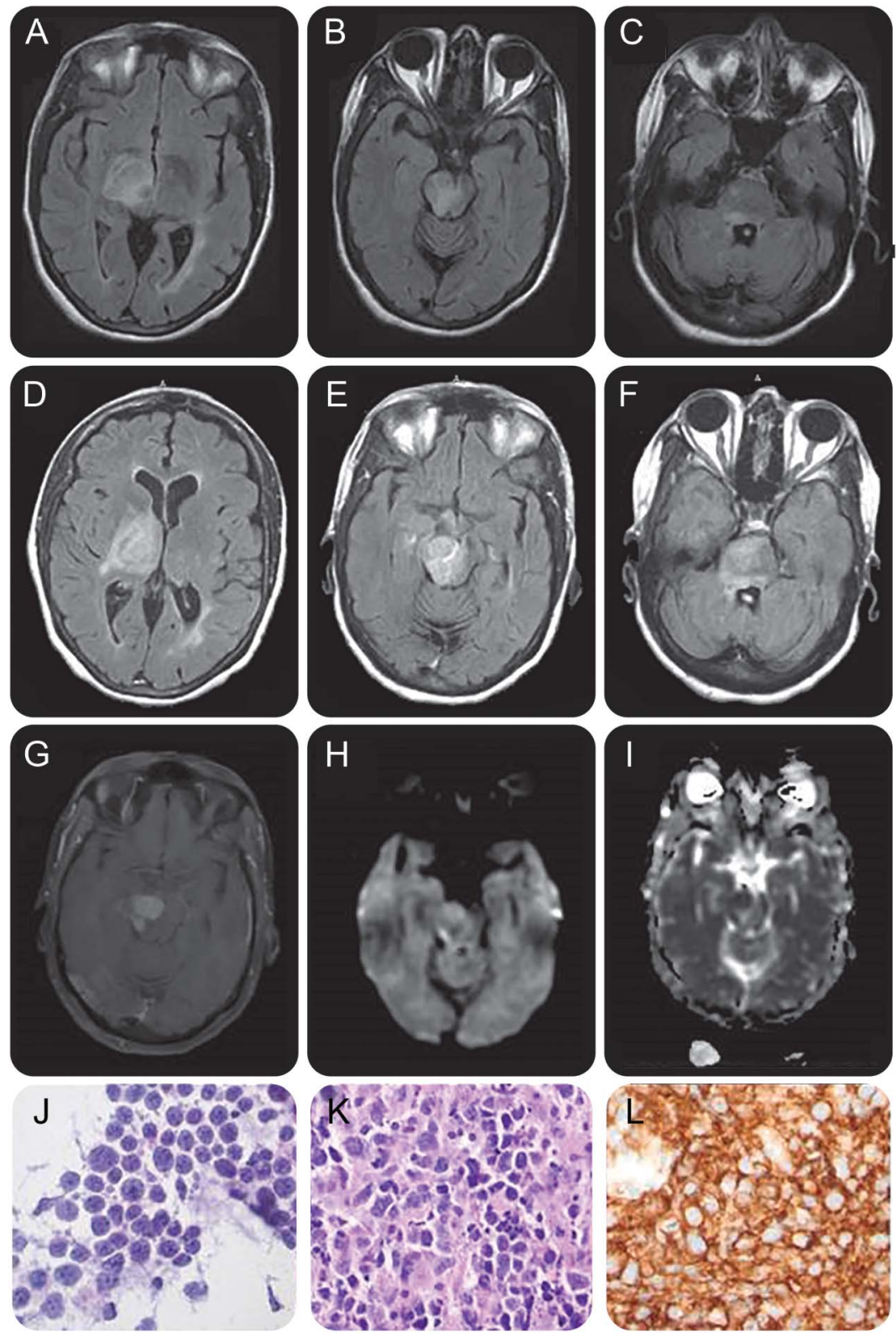

(A-C) MRI of brain obtained during initial admission in January 2017. Axial T2 fluid-attenuated inversion recovery (FLAIR) images show T2 hyperintense lesions involving thalamus (A), midbrain (B), and pons (C). (D-I) MRI of brain obtained during readmission in February 2017. Axial T2 FLAIR images show expansion of previous thalamo-mesencephalic lesion with increased edema (D-F) and homogeneous central contrast enhancement on T1 imaging (G). Diffusion-weighted imaging $(\mathrm{H})$ and apparent diffusion coefficient maps (I) show associated diffusion restriction. (J-L) Histopathology of large B-cell lymphoma. Hematoxylin \& eosin-stained intraoperative section demonstrates noncohesive cells with scant cytoplasm and large nuclei with prominent nucleoli $(\mathrm{J}, \times 400$ magnification). Hematoxylin \& eosin-stained permanent section demonstrates large cells with scant cytoplasm and large atypical nuclei with prominent nucleoli ( $\mathrm{K}, \times 400$ magnification). Large atypical cells show membranous CD20 staining, confirming diagnosis of large B-cell lymphoma ( $\mathrm{L}, \times 400$ magnification).

lymphoma. Stereotactic brain biopsy on hospital day 7 revealed CD5-negative, CD10-negative, and CD20positive diffuse large B-cell lymphoma (figure, J-L). CT chest, abdomen, and pelvis with and without contrast did not reveal evidence of systemic malignancy, and a diagnosis of primary CNS lymphoma (PCNSL) was confirmed. The patient was subsequently started on MATRIX protocol: rituximab (Rituxan; Biogen,
Cambridge, MA) day 1, methotrexate (Trexall; Teva, Petah Tikva, Israel) day 2, cytarabine (Depocyt; SigmaTau, Pomezia, Italy) days 3-4, thiotepa (Tepadina; ADIENNE, Lugano, Switzerland) day 5, and rituximab day 6 . Interferon $\beta$-1a was held until 6 months after rituximab. Left hemiparesis improved following chemotherapy to $3 / 5$ in the proximal left upper and lower extremities and 4-/5 distally. Right third cranial 
nerve palsy improved from complete to partial right ptosis and recovery of right eye adduction. The patient was discharged in March 2017 on hospital day 23 to a skilled nursing facility on filgrastim (Neupogen; Amgen, Thousand Oaks, CA) with antimicrobial prophylaxis for neutropenia, with planned readmission in 2 weeks for a second cycle of MATRIX protocol chemotherapy. Follow-up MRI brain without contrast after the fourth cycle of chemotherapy showed nearcomplete resolution of the prior thalamomesencephalic lesion and no mass effect, with only subtle residual T2 fluid-attenuated inversion recovery abnormality in the cerebral peduncle and posterior limb of the adjacent capsule.

DISCUSSION We describe a case of histologically confirmed PCNSL developing in a patient with RRMS maintained on interferon $\beta-1$. Although no definite link has been established between interferon $\beta$ and the development of B-cell lymphoma in patients with MS, several cases have been reported involving the development of PCNSL after initiation of interferon $\beta$ in patients with preexisting MS. ${ }^{1,2} \mathrm{We}$ address the difficulty of clinically differentiating PCNSL from tumefactive MS and discuss the role of anchoring bias, as well as pertinent radiologic characteristics that may be used to differentiate the two.

PCNSL unrelated to AIDS is a high-grade nonHodgkin B-cell neoplasm involving the CNS without evidence of systemic disease, which most commonly affects patients between 45 and 65 years of age. The differential diagnosis for a new contrastenhancing lesion in patients with MS is broad and includes non-neoplastic causes such as tumefactive MS, cerebral toxoplasmosis, and pyogenic abscess, as well as neoplastic causes such as PCNSL, glioma, meningioma, and other metastatic malignancies. Prompt diagnosis is imperative for PCNSL as it is highly chemosensitive but has a rapidly fatal course, with median survival of 1.5 months from time of diagnosis if untreated. However, diagnosing PCNSL in patients with preexisting MS is often difficult because of both anchoring bias and the radiologic overlap with tumefactive MS. Evaluation of CSF in PCNSL is nonspecific and often demonstrates lymphocytic pleocytosis, elevated protein, and normal or low glucose. The presence of neoplastic lymphoid cells in the CSF is specific but not sensitive, as malignant cells are found in fewer than $40 \%$ of cases. Clinically, both acute MS attacks and PCNSL are sensitive to corticosteroids. Substantial clinical improvement may be seen after corticosteroid administration in PCNSL, which may be interpreted as steroid-induced MS remission. However, continued dependence on corticosteroids, as in our patient, is unusual in MS but may be seen in
PCNSL and should raise the suspicion of lymphoma.

Both PCNSL and tumefactive MS share some common radiologic features, such as peripheral contrast enhancement, mass effect, and edema. However, even within these broad categories, differences between the MRI features of these 2 entities are evident. PCNSL produces hypointense or isointense lesions on unenhanced T1-weighted imaging and isointense to hyperintense lesions on T2-weighted imaging with linear enhancement along perivascular spaces and perifocal edema. Lesions are typically found in central hemispheric or periventricular white matter. ${ }^{3}$ Tumefactive MS, on the other hand, produces lesions greater than $2 \mathrm{~cm}$ that are primarily hypointense on unenhanced T1-weighted imaging, commonly located in a lobar distribution. ${ }^{4}$

Despite the large size of tumefactive MS lesions, PCNSL lesions are larger and have more mass effect than those of tumefactive MS, measured as either the maximum diameter on T2-weighted imaging or as the diameter of the lesion distinguishable from vasogenic edema on T1-weighted gadoliniumenhanced imaging. PCNSL may result in either subfalcine or uncal herniation, whereas tumefactive MS either causes no mass effect or results in mass effect limited to sulcal effacement. While both entities may have central or peripheral contrast enhancement, complete peripheral ring enhancement is more common in lymphoma, and incomplete peripheral ring enhancement, a hallmark of demyelination, is more common with tumefactive MS. In addition, diffusion restriction is more common with PCNSL, and it is usually central. However, diffusion restriction may be either peripheral or central in tumefactive demyelination. When peripheral diffusion restriction is present, incomplete restriction is suggestive of a tumefactive lesion, while complete restriction is more common with PCNSL (table e-1 at Neurology.org).

Characteristics that are less helpful in differentiating PCNSL from tumefactive lesions include patterns of central contrast enhancement and patterns of central diffusion restriction. While homogeneous central contrast enhancement is less common in tumefactive MS, heterogeneous central contrast enhancement may be seen in both entities. The presence of central diffusion restriction also strongly favors PCNSL. However, a homogeneous pattern of centrally restricted diffusion is almost certainly PCNSL, whereas a heterogeneous pattern is less informative (table e-1). In 2 prior case reports of PCNSL after interferon $\beta-1 \mathrm{a}$ in patients with preexisting MS, one patient presented with a homogeneously enhancing lesion in the frontal lobes involving the corpus callosum causing both mass effect and vasogenic 
edema, ${ }^{2}$ while the other patient presented with multiple ring-enhancing lesions with heterogeneous central enhancement. ${ }^{1}$ In these prior cases, intervals between the start of interferon $\beta-1 \mathrm{a}$ and PCNSL diagnosis ranged from 12 to 18 months. However, as illustrated by our patient, PCNSL diagnosis may be observed as long as 10 years after the start of interferon $\beta$-1a.

Current clinical evidence does not support a definitive link between non-Hodgkin lymphoma and treatment of MS with interferon $\beta .{ }^{5}$ However, a pathophysiologic link may exist between B-cell survival in PCNSL and proteins present in the CNS of patients with MS. Various factors known to support B-cell survival, including B-cell activating factor (BAFF), CXCL13, interleukin (IL)-6, IL-10, and IL-15, are upregulated in the CSF of patients with MS. ${ }^{6,7} \mathrm{MS}$ treatment with disease-modifying therapies (DMTs) such as interferon $\beta$ may theoretically further increase the risk of abnormal B-cell proliferation due to DMT immunomodulatory and immunosuppressive effects. Reports of PCNSL occurring in otherwise immunocompetent patients on immunosuppressive therapy support this theory. ${ }^{8}$ Interferon $\beta-1 \mathrm{a}$, in particular, increases IL-10 production, ${ }^{9}$ which exerts beneficial effects on the treatment of MS through regulation of B- and T-cell function and modulation of dendritic cell migration and macrophage activation, but it also prevents B-cell apoptosis for activated B cells. Secretion of BAFF, an NF- $\mathrm{B}$ activator essential for B-cell survival, may also be upregulated following stimulation with interferon in MS plaques. ${ }^{10}$ Thus, although current clinical evidence does not support a definitive link between PCNSL and interferon $\beta$ therapy, cellular studies suggest biological plausibility and a need for further investigation.

\section{AUTHOR CONTRIBUTIONS}

Dr. Chiang: acquisition of data, original manuscript draft, and critical revision of the manuscript. Dr. Kesari: original manuscript draft and critical revision of the manuscript. Dr. Bradshaw: acquisition of data and critical revision of the manuscript. Dr. Chen: critical revision of the manuscript. Dr. Samudralwar: critical revision of the manuscript. Dr. Alobaidy: critical revision of the manuscript. Dr. Kass: study supervision and critical revision of the manuscript.

\section{ACKNOWLEDGMENT}

Dr. Jerry Clay Goodman, MD, provided preparation and histopathology slides.

\section{STUDY FUNDING}

No targeted funding reported.

\section{DISCLOSURE}

The authors report no disclosures relevant to the manuscript. Go to Neurology.org for full disclosures.

\section{REFERENCES}

1. Yang J, Wu S. Multiple sclerosis preceding CNS lymphoma: a case report. Acta Neurol Taiwanica 2007;16:92.

2. Lyons MK, Boucher OK, Birch BD, Patel NP. The development of primary central nervous system B-cell lymphoma in multiple sclerosis. Neurohospitalist 2011;1: 133-136.

3. Haldorsen I, Espeland A, Larsson EM. Central nervous system lymphoma: characteristic findings on traditional and advanced imaging. Am J Neuroradiology 2011;32: 984-992.

4. Lucchinetti CF, Gavrilova RH, Metz I, et al. Clinical and radiographic spectrum of pathologically confirmed tumefactive multiple sclerosis. Brain 2008;131:1759-1775.

5. Sandberg-Wollheim M, Kornmann G, Bischof D, Moraga MS, Hennessy B, Alteri E. The risk of malignancy is not increased in patients with multiple sclerosis treated with subcutaneous interferon beta-la: analysis of data from clinical trial and post-marketing surveillance settings. Mult Scler 2011;17:431-440.

6. Ragheb S, Li Y, Simon K, et al. Multiple sclerosis: BAFF and CXCL13 in cerebrospinal fluid. Mult Scler 2011;17: 819-829.

7. Rentzos M, Cambouri C, Rombos A, et al. IL-15 is elevated in serum and cerebrospinal fluid of patients with multiple sclerosis. J Neurol Sci 2006;241:25-29.

8. Kleinschmidt-DeMasters BK, Damek DM, Lillehei KO, Dogan A, Giannini C. Epstein Barr virus-associated primary CNS lymphomas in elderly patients on immunosuppressive medications. J Neuropathol Exp Neurol 2008;67: 1103-1111.

9. Huang H, Ito K, Dangond F, Dhib-Jalbut S. Effect of interferon beta-1a on B7.1 and B7.2 B-cell expression and its impact on T-cell proliferation. J Neuroimmunol 2013;258:27-31.

10. Krumbholz M, Theil D, Derfuss T, et al. BAFF is produced by astrocytes and up-regulated in multiple sclerosis lesions and primary central nervous system lymphoma. J Exp Med 2005;201:195-200. 


\section{Neurology}

\section{Pearls \& Oy-sters: CNS lymphoma in a patient with relapsing-remitting multiple sclerosis treated with interferon}

Sharon Chiang, Navin K. Kesari, Anthony Bradshaw, et al. Neurology 2017;89;e210-e213

DOI 10.1212/WNL.0000000000004579

This information is current as of October 23, 2017

\begin{tabular}{|c|c|}
\hline $\begin{array}{l}\text { Updated Information \& } \\
\text { Services }\end{array}$ & $\begin{array}{l}\text { including high resolution figures, can be found at: } \\
\text { http://n.neurology.org/content/89/17/e210.full }\end{array}$ \\
\hline Supplementary Material & $\begin{array}{l}\text { Supplementary material can be found at: } \\
\text { http://n.neurology.org/content/suppl/2017/10/19/WNL.0000000000004 } \\
\text { 579.DC1 }\end{array}$ \\
\hline References & $\begin{array}{l}\text { This article cites } 10 \text { articles, } 2 \text { of which you can access for free at: } \\
\text { http://n.neurology.org/content/89/17/e210.full\#ref-list-1 }\end{array}$ \\
\hline Subspecialty Collections & $\begin{array}{l}\text { This article, along with others on similar topics, appears in the } \\
\text { following collection(s): } \\
\text { Multiple sclerosis } \\
\text { http://n.neurology.org/cgi/collection/multiple_sclerosis } \\
\text { Primary brain tumor/ } \\
\text { http://n.neurology.org/cgi/collection/primary_brain_tumor }\end{array}$ \\
\hline Permissions \& Licensing & $\begin{array}{l}\text { Information about reproducing this article in parts (figures,tables) or in } \\
\text { its entirety can be found online at: } \\
\text { http://www.neurology.org/about/about_the_journal\#permissions }\end{array}$ \\
\hline Reprints & $\begin{array}{l}\text { Information about ordering reprints can be found online: } \\
\text { http://n.neurology.org/subscribers/advertise }\end{array}$ \\
\hline
\end{tabular}

Neurology ${ }^{\circledR}$ is the official journal of the American Academy of Neurology. Published continuously since 1951, it is now a weekly with 48 issues per year. Copyright @ 2017 American Academy of Neurology. All rights reserved. Print ISSN: 0028-3878. Online ISSN: 1526-632X.

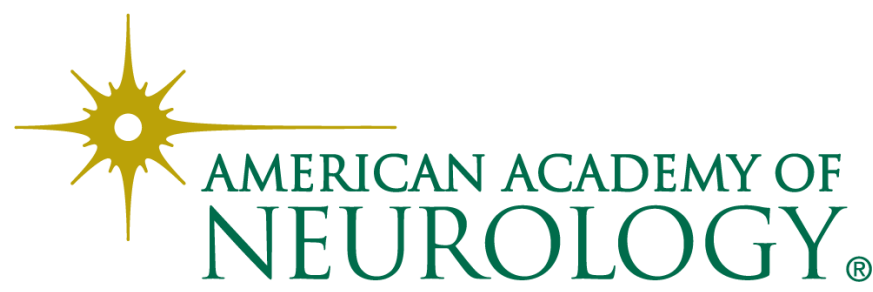

